\title{
Type F Congenital Quadricuspid Aortic Valve: A Very Rare Case Diagnosed by 3-dimenional Transoesophageal Echocardiography
}

\author{
Pankaj Garg*, Hazlyna Kamaruddin, Rachel Orme and Victoria Watt
}

Cardio-thoracic Unit, Chesterman Wing, Northern General Hospital, Herries Road, Sheffield, South Yorkshire, England S5 7AU

\begin{abstract}
Congenital quadricuspid aortic valve (QAV) is a rare cardiac anomaly. Several different anatomical variations of a quadricuspid aortic valve have been described. Aortic regurgitation is the predominant valvular dysfunction associated with QAV and patients tend to present in their $5^{\text {th }}$ or $6^{\text {th }}$ decade of life. This anomaly is rarely picked up by transthoracic echocardiogram (TTE). A comprehensive transoesophageal echocardiography (TOE) study is more likely to diagnose it. We describe a very rare type of QAV - Type $\mathrm{F}$ in a 52-year-old lady who presented with symptoms of shortness of breath and pre-syncope. We include TOE images and intra-operative valve images.
\end{abstract}

Keywords: 3D, Aortic Regurgitation, Congenital Heart Disease, Transoesophageal Echocardiography, Type F, Quadricuspid Aortic Valve.

\section{INTRODUCTION}

Quadricuspid aortic valve is a rare cardiac malformation, with an estimated incidence of 0.0031 to $0.043 \%$ of all congenital heart disease. It usually appears as an isolated congenital anomaly [1-3]. The Mayo Clinic has noted an incidence of $1 \%$ in a review of patients undergoing surgery for pure aortic regurgitation [4]. However, QAV may also be associated with other malformations, the most common being coronary artery anomalies $[5,6]$. QAV was mainly an incidental finding at open-heart surgery or at autopsy in the past [7].

\section{CASE REPORT}

A 52-year-old lady presented to our centre for echocardiogram from her primary-care-physician because he elicited a cardiac murmur. She had history of worsening breathlessness over a period of 7 years. She also had a history of pre-syncope.

She had a standard transthoracic echocardiogram (TTE), which revealed that her left ventricle (LV) is dilated with evidence of significant systolic dilatation (LV internal diameter systolic $55 \mathrm{~mm}$ ) associated with severe systolic impairment with an ejection fraction of 33\% (Simpson's Bi-plane method). The aortic valve appeared to be bicuspid on sub-costal views. The parasternal views of the aortic valve were somewhat limited. There was evidence of severe aortic regurgitation (AR) with a central regurgitant jet, which occupied greater than $65 \%$ of the LV outflow tract and there was clear flow reversal in the aortic arch and descending

*Address correspondence to this author at the Department of Cardiology, Chesterman Wing, Northern General Hospital, Sheffield Teaching Hospitals NHS Foundation Trust, Herries Road, Sheffield, S5 7AU, England;

Tel: 01142714950; Fax: 0114 2610350; E-mail: pankajvic@ gmail.com aorta. In addition to these findings there is also mild mitral regurgitation (MR) and preserved right ventricular (RV) systolic function. She also informed us that mother had aortic root pathology and had to have aortic root replacement surgery. This hinted to hereditary congenital aortic or aortic valve pathology. She was admitted to our unit and received heart failure treatment and consequently had transoesophageal echocardiography (TOE) (Philips IE33 using 3D-TOE probe).

\section{TOE ACQUISITION AND RESULTS}

In aortic short-axis views she has quadricuspid aortic valve with 4 sinuses. We identified that she had 2 equal larger cusps and 2 unequal smaller cusps, consistent with type F QAV (Figs. 1, 2). 3D zoom data was acquired in the AV long-axis views. TOE confirmed the finding of severe

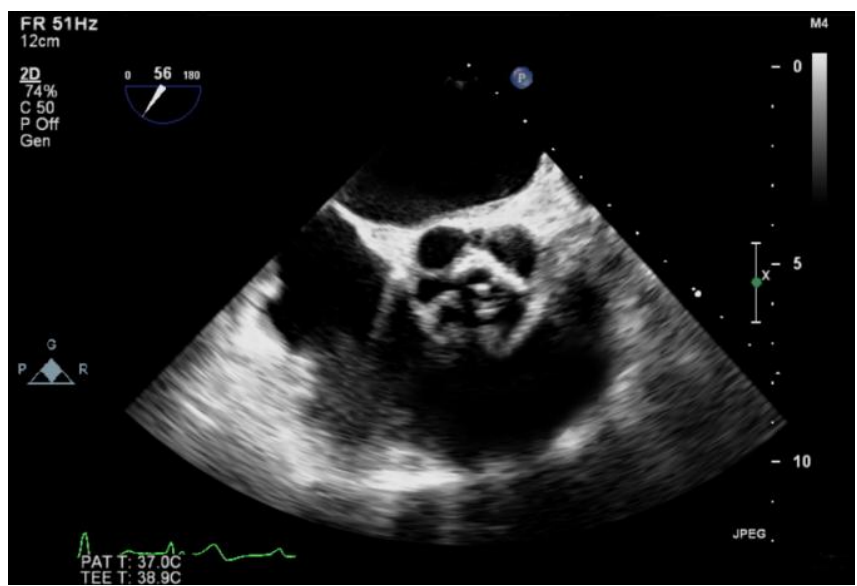

Fig. (1). 2-Dimensional diastolic short-axis view of quadricuspid aortic valve on TOE. 
AR (Fig. 3). This 3D data was later edited on offline QLAB Software tool to acquire aortic valve views from the aortic root (Fig. 4, Video 1).

Once she was stabilised with heart failure treatment, she had prompt surgery to replace her aortic valve (Fig. 5). She made un-eventful recovery and was discharged one-week after AV-surgery.

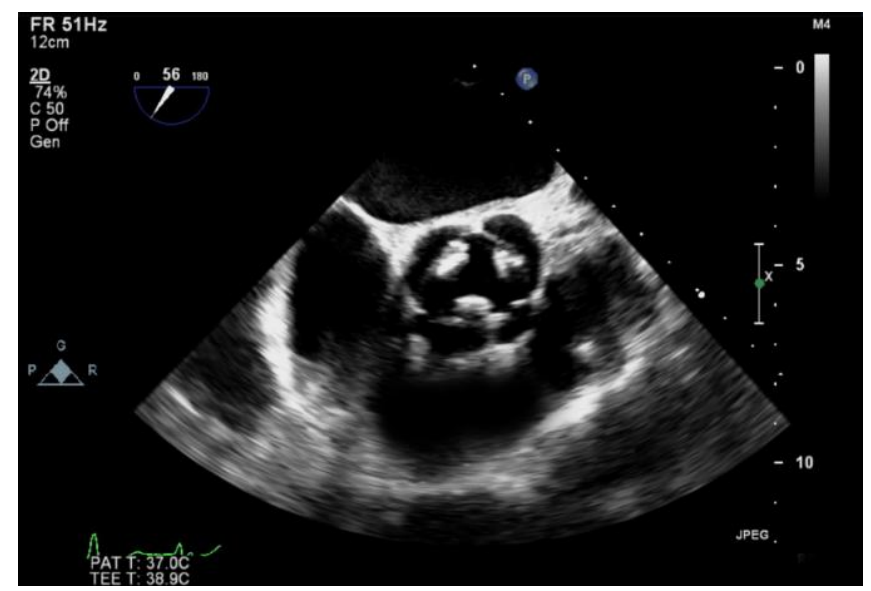

Fig. (2). 2-Dimensional systolic short-axis view of quadricuspid aortic valve on TOE.

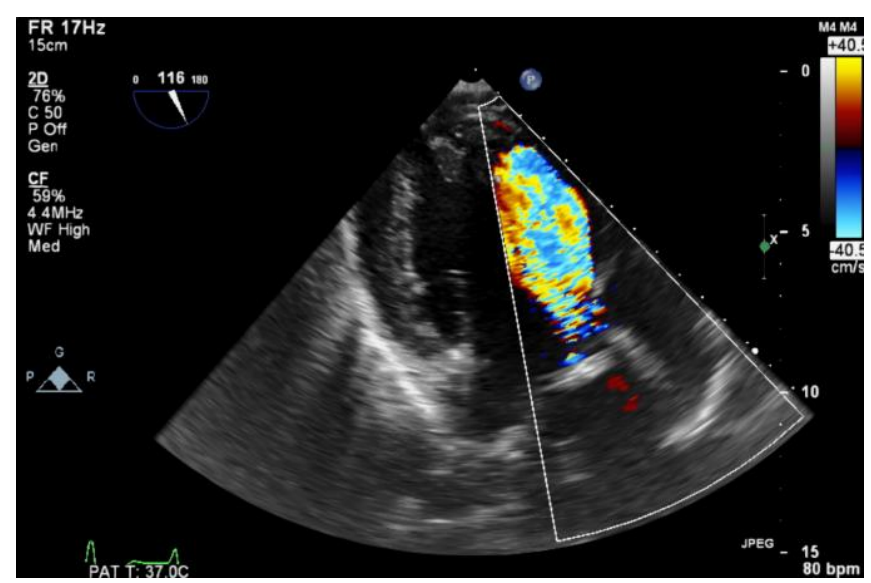

Fig. (3). Trans-gastric colour doppler view of severe aortic regurgitation.

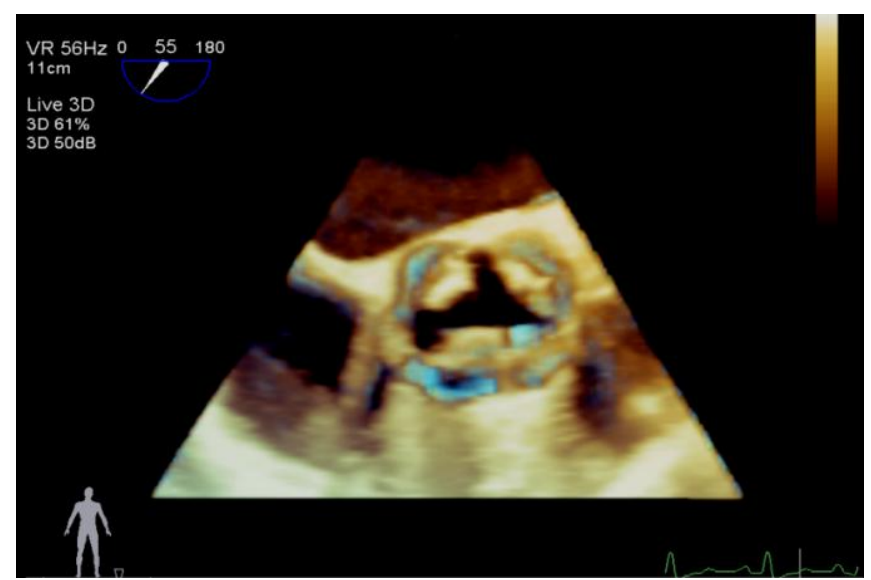

Fig. (4). 3-Dimensional view of aortic valve from the aortic root clarifying the anatomy of quadricuspid aortic valve.

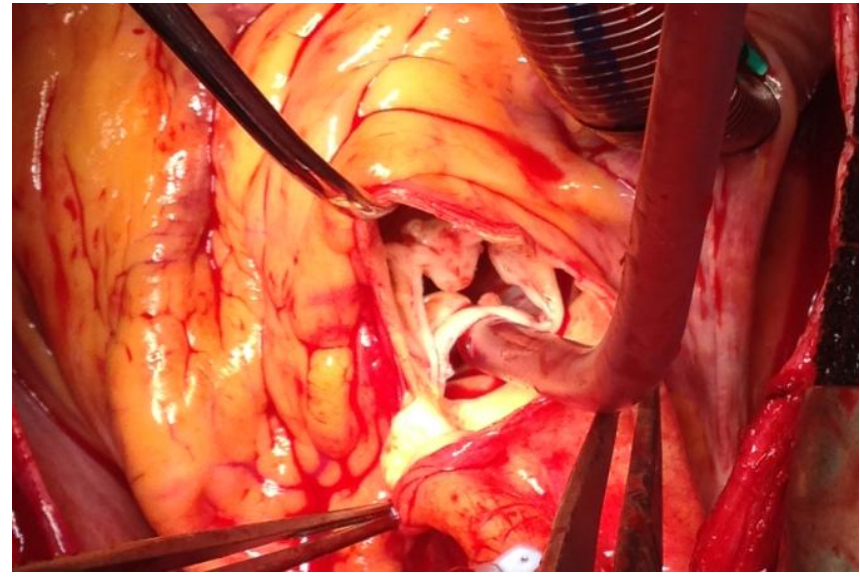

Fig. (5). Intra-operative view of the quadricuspid aortic valve.

\section{LITERATURE SEARCH}

We carried out a literature review to find how many type $\mathrm{F}$ cases have been reported on MEDLINE. Searches were carried out using the following words - 'quadricuspid AND aortic AND valve AND type AND F'. Three case reports were identified [8-10]. Two cases were mainly diagnosed as part of work-up for surgical repair for aortic incompetency $[8,9]$. One case was of a 26-year old woman who presented with infective endocarditis and was diagnosed with type $\mathrm{F}$ QAV on TOE [10]. We did not identify any case, which had heredity link with aortopathy or any aortic valve disease.

\section{DISCUSSION AND REVIEW}

Recent advances in non-invasive cardiovascular imaging have enabled us to define the anatomy of QAV with high accuracy. Around 200, mainly adult cases have been described in the literature. A major review included 184 patients, with a slight male predominance [5]. Case reports or series of children being diagnosed with this congenital heart anomaly are generally small [11]. More than half of the patients with this abnormality will develop aortic insufficiency in adulthood. It is vital that patients with QAV who present with progressive AR undergo valve replacement or repair at appropriate time. Hence, it is important to promptly detect this malformation and arrange appropriate investigative follow up.

\section{CLASSIFICATION OF QUADRICUSPID AORTIC VALVE}

According to the anatomy of the 4 cusps, Hurwitz and Roberts categorized QAV into 7 subtypes (A to G) (Table 1). [1]. Almost $85 \%$ of cases are of type A, B or C [1].

The morphogenesis of QAV is unknown in man. However, an animal case-report supported the hypothesis that QAV result from the division of 1 of the 3 mesenchymal anlagen that give rise to the normal aortic valves [12].

The physiopathology of the QAV dysfunction is poorly understood. Anatomical abnormalities of the cusps could induce unequal shear stress leading to fibrotic changes and incomplete coaptation [2]. However, insufficiency is also observed in cases of quadricuspid valve with 4 equal cusps 
Table 1. Hurwitz and Roberts' anatomical classification of QAV. (Permission for re-prints obtained from Elsevier Limited, license number: 3293700398552).

\begin{tabular}{|c|l|}
\hline Type & \multicolumn{1}{|c|}{ Description } \\
\hline \hline A & Four equal cusps \\
\hline B & Three equal cusps and one smaller cusp \\
\hline C & Two equal larger cusps and two equal smaller cusps \\
\hline D & One large, two intermediate and one small cusp \\
\hline E & Three equal cusps and one larger cusp \\
\hline F & Two equal larger cusps and two unequal smaller cusps \\
\hline G & Four unequal cusps \\
\hline
\end{tabular}

[2]. As in bicuspid valve, regurgitation of an abnormal aortic valve may also occur as a result of a prolapse of the layer of the cusps or be associated with aortic root dilatation [13]. Aortic root dilatation in patients with QAV was reported in only 1 case [14]. Aortic valve regurgitation may induce diffuse dilatation of the ascending aorta. The opposite- aortic regurgitation secondary to aortic root dilatation - may also occur as a result from disruption or dissolution of elastic tissue within the aortic ring, as this structure provides the main support for the valve cusps [13].

\section{CONCLUSION}

It is worth noting that TTE could not provide the relevant AV anatomy. Both 2-dimentional and 3-dimentional TOE are first choice of investigation to make appropriate assessment of QAV. Prompt symptom recognition is pivotal and timed intervention can save patient's life. Our case of type F QAV also provides a possible first link between hereditary aortic root disease and QAV.

\section{ABBREVIATIONS}

$\begin{array}{lll}\mathrm{AR} & = & \text { Aortic regurgitation } \\ \mathrm{LV} & = & \text { Left ventricle } \\ \text { QAV } & = & \text { Quadricuspid aortic valve }\end{array}$

$\mathrm{TTE}=\quad$ Transthoracic echocardiogram

TOE = Transoesophageal echocardiography

\section{CONFLICT OF INTEREST}

All authors declare that they have no competing interests.

\section{ACKNOWLEDGEMENTS}

We are obliged to Mr Stefano Forlani (Cardiac Surgeon, Sheffield Teaching Hospitals NHS Foundation Trust) for providing us with the intra-operative picture of aortic valve.

\section{REFERENCES}

[1] Hurwitz LE, Roberts WC. Quadricuspid semilunar valve. Am J Cardiol 1973; 31: 623-6.

[2] Feldman BJ, Khandheria BK, Warnes CA, et al. Incidence, description and functional assessment of isolated quadricuspid aortic valves. Am J Cardiol 1990; 65: 937-8.

[3] Holt NF, Sivarajan M, Mandapati D, et al. Quadricuspid aortic valve with aortic insufficiency: case report and review of the literature. J Card Surg 2007; 22: 235-7.

[4] Olson LJ, Subramanian R, Edwards WD. Surgical pathology of pure aortic insufficiency: a study of 225 cases. Mayo Clin Proc 1984; 59: 835e41.

[5] Gulyasy B, López-Candales A, Reis SE, et al. Quadricuspid aortic valve: An unusual echocardiographic finding and a review of the literature. Int J Cardiol 2006; 132: 68-71.

[6] Tutarel O. The quadricuspid aortic valve: a comprehensive review. J Heart Valve Dis 2004; 13: 534-7.

[7] Davia JE, Fenoglio JJ, DeCastro CM, et al. Quadricuspid semilunar valves. Chest 1977; 72: 186-9.

[8] Tang YF, Xu JB, Han L, et al. Congenital quadricuspid aortic valve: analysis of 11 surgical cases. Chin Med J (Engl) 2011; 124: 2779-81.

[9] Scrofani R, Pettinari M, Vanelli P, et al. Type F quadricuspid aortic valve: surgical treatment of a rare cause of aortic valve disease. J Cardiovasc Med (Hagerstown) 2008; 9: 311-3.

[10] Takeda N, Ohtaki E, Kasegawa H, et al. Infective endocarditis associated with quadricuspid aortic valve. Jpn Heart J 2003; 44: 441-5.

[11] Di Pino A, Gitto P, Silvia A, et al. Congenital quadricuspid aortic valve in children. Cardiol Young 2008; 18: 324-7.

[12] Fernández B, Durán AC, Martire A, et al. New embryological evidence for the formation of quadricuspid aortic valves in the Syrian hamster (Mesocricetus auratus). J Comp Pathol 1999; 121: 89-94.

[13] Ward C. Clinical significance of the bicuspid aortic valve. Heart 2000; 83: 81e5.

[14] Cooke JC, Dupuche DR, Gay TJ. Quadricuspid aortic valve. Echocardiography 2000; 17: 699 .

Received: January 19, 2014
C Garg et al.; Licensee Bentham Open.

This is an open access article licensed under the terms of the Creative Commons Attribution Non-Commercial License (http://creativecommons.org/licenses/ by-nc/3.0/) which permits unrestricted, non-commercial use, distribution and reproduction in any medium, provided the work is properly cited. 